\title{
Linguagem e exclusão: o discurso da mídia sobre o professor e a escola
}

\section{Language and exclusion: media discourse on Brazilian teachers and schools}

Anna Maria Grammatico Carmagnani*

Universidade de São Paulo - USP

RESUMO: O foco deste estudo é o discurso produzido pela mídia acerca da escola brasileira, sobretudo o discurso sobre professores e o modo como são representados. Nossa análise mostra que os professores são incluidos nos discursos produzidos para serem excluídos, tendo em vista que são apontados como os responsáveis pela fragilidade e problemas que o sistema educacional vem sofrendo. O objetivo do texto é discutir essas representações e o tipo de sujeito que o discurso da mídia constrói, questionando outros aspectos que são cruciais para a compreensão de nossas identidades.

PALAVRAS-CHAVE: identidade, professores, discurso da mídia, educação.

ABSTRACT: The focus of this study is the discourse produced by the media about Brazilian schools, specially the discourse about teachers and the way they are represented. Our analysis shows that teachers are included in the discourses produced to be excluded as they are pointed as responsible for the weaknesses and problems the Brazilian educational system has been facing. This text has the objective of discussing those representations and the kind of subject media discourse is constructing, questioning other aspects that are crucial for the understanding of our identities.

KEYWORDS: identity, teachers, media discourse, education.

Este trabalho parte do pressuposto de que a(s) identidade(s) em nossa sociedade não são fixas, tampouco homogêneas; ao contrário, elas são complexas, contraditórias e construídas ao longo de nossas vidas através da linguagem. Adotando uma perspectiva psicanalítica, partimos da premissa de que nossa(s) identidade(s) vinculam-se irremediavelmente ao Outro que nos constitui enquanto sujeitos. Desse modo, a imagem que construímos sobre nós, isto é, nossa identidade, depende desse Outro a quem queremos atender e, ao mesmo

*amcarmag@usp.br 
tempo, situa-nos, permite-nos um sentimento de pertencimento, ou nos exclui de modos diversos, provocando identificaçôes com relação ao que acreditamos ser, ao que acreditamos que o Outro quer que sejamos ou, negativamente, ao que o Outro não acredita que sejamos, não permite que sejamos.

O foco do estudo é o discurso midiático sobre a escola, sobretudo o discurso sobre os professores que vêm sendo atacados e colocados como os responsáveis pela crise da educação brasileira. A perspectiva teórica adotada baseia-se na interface dos estudos de discurso, sobretudo os trabalhos de Michel Foucault, e da psicanálise lacaniana. Constatamos, pelas pesquisas que vimos desenvolvendo, que os discursos que circulam em nossa sociedade através da mídia não apenas impedem o sentimento de pertencimento desse professor à comunidade de professores da qual naturalmente faria parte, mas lhe impõem o silêncio, o controle, a exclusão pela inclusão. Em outras palavras, o professor é incluído para ser criticado, responsabilizado pelas mazelas da educação, e é excluído pelo discurso que o desqualifica e desmoraliza. Nossa análise visa problematizar o discurso sobre a escola e o tipo de sujeito da educação que está sendo construído, questionando outros aspectos cruciais que afetam nossas identidades neste início de século.

\section{Mídia e regime(s) de verdade(s)}

Um dos conceitos que utilizamos nesta reflexão é o defendido por Foucault (1979 [1990]) sobre as relações saber-poder e o(s) regime(s) de verdade. Para o autor, a verdade não existe fora do poder:

[a] verdade é deste mundo; ela é produzida nele graças a múltiplas coerçóes e nele produz efeitos regulamentados de poder. Cada sociedade tem seu regime de verdade, sua "política geral" de verdade: isto é, os tipos de discurso que ela acolhe e faz funcionar como verdadeiros; os mecanismos e as instâncias que permitem distinguir os enunciados verdadeiros dos falsos, a maneira como se sanciona uns e outros; as técnicas e os procedimentos que são valorizados para a obtenção da verdade; o estatuto daqueles que têm o encargo de dizer o que funciona como verdadeiro (FOUCAULT, 1979 [1990, p. 12]).

Neste trabalho, tomamos a mídia como grande difusora de regime(s) de verdade(s) sobre a escola: revistas semanais, jornais impressos, jornais online e programas ou propagandas ditas educativas buscam estabelecer algumas verdades a respeito da escola. 
Um outro conceito de Foucault aqui utilizado é o da "tecnologia política dos indivíduos" (FOUCAULT, 2004, p. 308):

[d]o ponto de vista do Estado, o indivíduo apenas existe quando ele promove diretamente uma mudança, mesmo que mínima, no poderio do Estado, seja esta positiva ou negativa. O Estado tem que se ocupar com o indivíduo apenas quando ele pode introduzir tal mudança. E tanto o Estado lhe pede para viver, trabalhar, produzir e consumir, como lhe exige morrer.

No estudo mencionado, Foucault levanta questôes acerca das possíveis maneiras que, por meio de uma tecnologia política, nós nos reconhecemos como parte de uma sociedade, uma nação ou um Estado. Discute, assim, os modos pelos quais somos tutelados para a promoção da integração indivíduoEstado, descrevendo as formas pelas quais isso foi possível ao longo da história. A implicação dessa reflexão com o nosso estudo é o fato de entendermos que a mídia, além de desempenhar a função de difusora de verdade(s), funciona como reguladora do poder do Estado, no caso, o "controle" (positivo ou negativo) dos indivíduos para sua maior funcionalidade com esse Estado. E isso se dá por meio dos vários textos (orais e escritos) veiculados repetidamente nos vários meios de comunicação.

Vários exemplos de revistas semanais podem ser destacados, sobretudo em períodos de avaliações nacionais e internacionais (cf. ANEXOS A e B). $\mathrm{Na}$ primeira revista (Época), a apresentação do aluno com um chapéu de "burro" é utilizada para fazer críticas aos livros didáticos utilizados nas escolas. $\mathrm{Na}$ reportagem em questão, os professores são também responsabilizados pela escolha do material e visão parcial do conteúdo. Contudo, a crítica é, a nosso ver, grosseira, não só pela escolha da imagem da capa, mas pela abordagem feita ao tema na reportagem.

A segunda revista (Veja, ANEXO B), por sua vez, retoma a imagem do aluno despreparado que não sabe nem escrever corretamente, com a manchete "Os erros não são só dele", seguida de um subtítulo: "Os estudantes brasileiros são os piores nos rankings internacionais mas... mais de $90 \%$ dos professores e pais aprovam as escolas". Na reportagem em questão, pais e professores são criticados por não perceberem o despreparo dos estudantes.

Destacaríamos também as opiniōes publicadas na revista Época de $17 \mathrm{de}$ abril de 2006. Na matéria em questão, para opinar sobre um problema brasileiro, alguns especialistas estrangeiros (economistas) são convocados para diagnosticar as possíveis razões de nossa "crise": 
Quanto mais inclusivo for o alcance da educação básica e dos serviços de saúde, maior a probabilidade de que os pobres tenham uma chance de superar a penúria (Amartya Sen, prêmio Nobel de Economia em 1998, Revista Época, 17/04/2006).

e

Sem investimentos em educação, fica praticamente impossível assimilar novas tecnologias (Joseph Stiglitz, Prêmio Nobel em Economia de 2001, Revista Época, 17/04/2006, p. 36).

Seguindo o raciocínio de Peters (1994, p.213), "não existe, talvez, melhor exemplo da extensão do mercado a novas áreas da vida social que o campo da educação", isto é, a educação no modelo neoliberal

não é tratada de forma diferente de qualquer outro serviço ou mercadoria. Nessa nova situação, as pessoas são pressionadas para se envolver em novas atividades que são amplamente definidas por novas práticas discursivas tais como marketing, publicidade e gerência.

Ainda segundo Peters (Op. cit.),

o Estado tem retido seu poder institucional através de uma nova forma de individualização, na qual os seres humanos transformam-se em sujeitos do mercado, sob o signo do Homo economicus. E, esta é a base para compreender o "governo dos indivíduos" na educação como uma técnica ou forma de poder que é promovida através da adoção de formas de mercado.

O que é intrigante no exemplo fornecido é que o discurso de autoridade é feito por economistas ganhadores do Prêmio Nobel, estrangeiros que falam da educação de uma perspectiva globalizada, partindo do pressuposto de que o que é bom para outros países é bom para nós, e não por especialistas em Educação. Nesse discurso também está implicado que nossas autoridades não são capazes de fornecer diretrizes para nossa educação, mesmo porque não há nenhum Prêmio Nobel entre eles. Um dos sentidos produzidos nesse e em outros textos é o baixo valor atribuído aos profissionais brasileiros.

O título da reportagem (cf. ANEXO C) simplifica o problema vivenciado, apesar de tocar na questão da política educacional:

\section{É TÃO DIFÍCIL COPIAR?}

Exemplos internacionais de sucesso mostram que o Brasil, para dar certo, precisa de um projeto nacional de educação que não seja trocado a cada mudança de governo (Época, 17/04/2006) 
Interessante observar como a reportagem acaba por fazer outras comparações do Brasil com países nos quais a educação tem um projeto "bem sucedido". O contraste das imagens apresentadas não deixa dúvidas para o leitor que já está constituído pelo discurso da importância das novas tecnologias (cf. ANEXO D). As imagens contrapõem com maior evidência professores em treinamento na Coréia do Sul e um professor brasileiro em sala de aula. Ao lado dessas imagens, a foto de crianças coreanas tocando violino.

A seguinte legenda guia a leitura:

\section{EXEMPLOS}

Há 40 anos, o PIB per capita da Coréia do Sul era metade do brasileiro. Hoje, é o dobro, graças ao investimento em educação. Professores recebem treinamento de internet. Alunos estudam até 15 horas por dia e têm aulas de música. No Brasil, professores e alunos ainda dependem quase exclusivamente da lousa (Época, 17/04/2006, p. 37).

Após avaliar várias questóes relativas à escola (espaço físico, etc.), o repórter fala dos professores e dos resultados obtidos:

É difícil melhorar esse quadro com professores desvalorizados e desmotivados. O professor de escola pública recebe em média $\mathrm{R} \$ 550$ por mês, menos do que ganha um cobrador de ônibus em São Paulo. Com salários assim, fica difícil investir no aprimoramento profissional. A grande maioria não tem computador em casa, e $60 \%$ deles não usam a internet.

Ao professor cabe um quadro que resume sua penúria:

\section{DESVALORIZADOS}

Professores ganham mal e têm baixa valorização

$68 \%$ fizeram faculdade

$32 \%$ pararam no ensino médio

$60 \%$ nunca usam internet

$65 \%$ têm renda familiar entre $\mathrm{R} \$ 600$ e $\mathrm{R} \$ 3$ mil

$36 \%$ não lêem jornal regularmente

A reportagem aponta soluções: transferência de recursos do ensino superior para o básico. Mas aponta que essa é "uma questão politicamente explosiva, pois os professores e funcionários das universidades públicas são um grupo de interesse fortemente articulado e organizado" (p.42). 
Exemplos de outros países também são mencionados nas folhas amarelas da revista Veja, de 6 de agosto de 2008, com a entrevista realizada com Andreas Schleicher, responsável pela aplicação do PISA. ${ }^{1}$ A pergunta feita versa sobre a que o especialista atribui o "atraso da educação em países como o Brasil":

Os professores ainda conduzem suas aulas guiados muito mais pelas próprias ideologias do que por conhecimento científico. Na prática, eles escolhem seguir linhas pedagógicas motivados por nada além de crenças pessoais e deixam de enxergar aquilo que as pesquisas apontam como verdadeiramente eficaz. Fico perplexo com o fato de a neurociência ser tão ignorada pelos educadores. Pior ainda: os educadores são os maiores inimigos dessa ciência. Eles perdem um tempo precioso ao repudiá-la (Veja, 06/08/2008, Páginas amarelas).

Destacam-se nessa resposta a contraposição conhecimento científico $\mathrm{x}$ ideologia, como se o discurso da ciência, discurso verdadeiro, estivesse imune a qualquer tipo de ideologia. As crenças pessoais, usadas de forma geral, contrapõem-se também às verdades estabelecidas.

\section{O espaço da escola}

Segundo Foucault (1987 [1989, p. 134]), a organização de um espaço serial foi uma das grandes modificaçóes técnicas do ensino elementar:

Determinando lugares individuais, tornou possível o controle de cada um e o trabalho simultâneo de todos. Organizou uma nova economia do tempo de aprendizagem. Fez funcionar o espaço escolar como uma máquina de ensinar, mas também de vigiar, de hierarquizar, de recompensar.

Observe-se a citação mencionada por Foucault (Op. cit., p.135), retirada do L'Almanach populaire de La France, 1839:

\footnotetext{
${ }^{1}$ O Programa Internacional de Avaliação de Alunos - PISA - é realizado a cada três anos pela Organização para Cooperação e Desenvolvimento Econômico - OCDE, tendo como objetivo fornecer aos países participantes indicadores que possam ser comparados internacionalmente para subsidiar políticas de melhoria da educação. Participam do programa alunos de 15 anos de idade, matriculados a partir da $7^{\text {a }}$ série do ensino fundamental até a $3^{a}$ série do ensino médio.
} 
Haverá em todas as salas de aula lugares determinados para todos os escolares de todas as classes, de maneira que todos os da mesma classe sejam colocados num mesmo lugar e sempre fixo. Os escolares das liçōes mais adiantadas serão colocados nos bancos mais próximos da parede e em seguida os outros segundo a ordem das lições avançando para o meio da sala. Cada um dos alunos terá seu lugar marcado e nenhum o deixará nem trocará sem a ordem e o consentimento do inspetor das escolas. [Será preciso fazer com que] aqueles cujos pais são negligentes e têm piolhos fiquem separados dos que são limpos e não os têm; que um escolar leviano e distraído seja colocado entre dois bem comportados e ajuizados, que o libertino ou fique sozinho ou entre dois piedosos.

Essa descrição chama-nos a atenção pelo fato de que a escola ideal no século XIX, apesar da proposta de inclusão das grandes massas para o mercado de trabalho, excluía os alunos de modos similares aos da escola de nossos dias. Com relação ao professor, a distinção entre os bons e os maus também é mencionada em vários relatos. Em todos, como nos dias atuais, a idealização do espaço da sala de aula, de alunos e de professores, acabou por afastar a discussão das questóes mais importantes relativas à escola e formação de professores, ao salientar espaço físico, novas tecnologias, materiais sempre mais modernos, em detrimento dos sujeitos da educação e de suas identidades mutáveis e construídas ao longo de um processo extremamente complexo. Burchell (1993, apud PETERS, 1994, p. 220) fala do espaço da escola visto a partir de uma perspectiva neoliberal, não defendida por ele:

[...] exige-se que cada escola, individualmente, funcione cada vez mais como uma quase-empresa independentemente administrada, em competição com outras escolas. Elas são encorajadas a se esforçar por adquirir um status ou valor especial no mercado de serviços escolares. Elas têm que promover a si próprias para atrair mais alunos do tipo certo de forma que possam obter melhores resultados nos testes e possam, assim, continuar a atrair os alunos certos, enviados por "paisconsumidores", obtendo fundos crescentes do Estado e de fontes privadas $[\ldots]$

Exemplo disso são as matérias repetidas a cada ano sobre as "melhores escolas"; como mostra a chamada na capa da revista Veja SP, de 16 de abril de 2008 (cf. ANEXO E): 
O QUE AS 10 MELHORES ESCOLAS DA CIDADE TÊM EM COMUM

- Professores bem remunerados

- Jornada de estudos ampliada

- Atividades extracurriculares

CONHEÇA A FÓRMULA DE SUCESSO DOS COLÉGIOS PAULISTANOS CAMPEÓES DO ENEM

$\mathrm{Na}$ reportagem em questão, as escolas são apresentadas conforme a sua colocação. Outras informaçôes são dadas acerca de cada escola "campeã": número de alunos, mensalidade, seleção de alunos, seu "segredo de sucesso", corpo docente, infraestrutura, disciplina e endereço. As salas de aula, biblioteca e outros aspectos físicos da escola são mostrados através de fotos que funcionam como provas da qualidade apresentada.

A menção das campeãs é apresentada todos os anos, descrevendo um modelo de escola que exclui muitas outras, sobretudo as públicas, por apresentar modos de funcionamento muito distantes dessas e de outras escolas em regiōes menos privilegiadas. A remuneração e grau de estudo dos professores é sempre mencionada, e é desnecessário dizer que a diferença entre os professores "campeões" e os outros (grande parte dos professores do ensino público) é imensa. A esses últimos (os que não são "campeões") cabe a qualificação "Professor sabe nada" (título de uma reportagem publicada no jornal Folha de S.Paulo, em 30/05/2004, C8, assinada por Gilberto Dimenstein) à qual adicionaríamos "Professor ganha nada, professor vale nada" (palavras formuladas por professores em curso de atualização). ${ }^{2}$ É muito fácil deslizar para esses outros sentidos já que na perspectiva mercadológica, "as pessoas devem ser tratadas como maximizadores racionais da utilidade para reforçar seus próprios interesses (definidos em termos de posições mensuráveis de riqueza) na política, assim como em outros aspectos da conduta" (PETERS, 1994, p. 221). Constatamos, em cursos de atualização, como os profissionais constroem uma imagem negativa a respeito de si próprios a partir da reiteração de suas incapacidades, de seu fracasso, enfim, de seu despreparo profissional. Não se discute, contudo, o descaso das autoridades com relação à formação desse profissional e às condições materiais que dispõe para o exercício de sua atividade.

\footnotetext{
${ }^{2}$ Discuto esse tipo de formulação no texto "Identidade e formação de professores: a construção da posição sujeito-professor em cursos de atualização", Letras \& Letras, Revista da UFU, v. 9, p. 89-98, 2003.
} 
Para Peters (Op. cit.) estamos vivenciando uma nova metanarrativa, baseada numa nova visão de futuro e

a linguagem usada para sustentar essa visão é uma linguagem de excelência, inovação, melhoria e modernizaçāo, obter mais com menos, alfabetização tecnológica, revolução na informação e nas telecomunicaçôes, marketing e gerência internacionais, treinamento de habilidades, desempenho e empresa (p. 222, grifo nosso).

E, é interessante observar como esses termos vêm sendo cada vez mais utilizados com referência à educação.

Para Dufour (2005, p.183),

o mercado tem objetivamente interesse na flexibilidade e na precarização das identidades. Idealmente, o Mercado é o que deve poder fornecer, a qualquer um, em todos os lugares e a todo instante, todos os produtos que são supostos corresponder aos desejos, estranhamente compreendidos como desejos instantâneos e possíveis de satisfazer sem demora.

Tendo isso em mente, perguntaríamos: afinal, que sujeito da educação vem sendo construído?; que identidades são forjadas através desses discursos?

A partir da análise realizada, constatamos que o discurso da mídia vem construindo um sujeito da educação destituído de suas identificações prévias. No caso do professor, ele funciona como uma peça que deve ser aperfeiçoada para a obtenção de um produto final com qualidade (deve se desvencilhar de crenças, ideologias, etc.), enfim, ser uma máquina de ensino. Contudo, os investimentos, via-de-regra, são feitos em direções que não levam em conta suas necessidades reais, mas necessidades fabricadas para servir a outros interesses. Ao final, ambos - professores e autoridades - lamentam as suas perdas.

Observamos também que o trabalho do professor tem sido continuamente avaliado através de regras mercadológicas aplicadas em outros setores (provavelmente mais eficientes!); o trabalho deve ser "otimizado" e a "eficiência" premiada. Ao mesmo tempo, deve-se copiar modelos bem sucedidos em outros países em detrimento do legado cultural.

Uma outra lição é fornecida por esses textos, segundo os quais todos devem: a) estar atentos ao que os melhores no mundo e os melhores locais estão fazendo para não perder competitividade; b) buscar / perseguir sua inclusão nesse processo. Entendemos, contudo, que a perda, nesse caso, reside no fato 
de que não adianta imitar outros quando não conseguimos avaliar nossa própria situação. $\mathrm{O}$ bom profissional observa outras experiências e se apropria daquilo que o ajuda em seu contexto, a partir das próprias contingências. $\mathrm{O}$ "bom" professor não copia simplesmente; estabelece relações entre seu conhecimento de mundo e da disciplina específica na qual atua e o conhecimento de seu contexto. O "bom" professor questionaria o que de fato é "melhor" para sua escola, seus alunos. Nosso problema é que isso não tem sido feito.

Gostaríamos, portanto, de ressaltar que essa reflexão não visa redimir o professor de suas responsabilidades e dos problemas que, sabemos, vivencia na escola, nem sempre o local idealizado em seus cursos de Licenciatura. Não pretende, tampouco, negar o despreparo de muitos profissionais. Pretende, na verdade, funcionar como uma ação que questiona e denuncia os discursos que constroem identidades cada vez mais negativas sobre o professor e sua relação com a escola, excluindo-o de vários modos. Pretende, acima de tudo, defender a inclusão desse profissional nas discussões sobre os limites e as possibilidades da escola nos dias de hoje.

\section{Referências}

BURCHELL, G. Liberal Government and Techniques of the Self. Economy and Society, 22(3), p. 267-283, 1993.

DUFOUR, D.R. A arte de reduzir as cabeças: sobre a nova servidão na sociedade ultraliberal. Rio de Janeiro: Companhia de Freud, 2005. 216p.

ÉPOCA, São Paulo: Editora Globo, ed. 413, p. 36-42, abr. 2006.

ÉPOCA, São Paulo: Editora Globo, ed. 492, out. 2007.

FOUCAULT, M. Vigiar e punir: nascimento da prisão. 7. ed. Trad. Lígia Ponde Vassalo. Petrópolis: Vozes, 1989. 280p. (1ª ed. brasileira, 1987)

FOUCAULT, M. Microfisica do poder. 9. ed. Org. e trad. Roberto Machado. Rio de Janeiro: Editora Graal, 1990. 295p. (1 a ed. brasileira, 1979)

FOUCAULT, M. Ética, sexualidade e política. Ditos e escritos - V. 5. Manoel Barros Motta (Org.). Rio de Janeiro: Forense Universitária, 2004. 322p.

PETERS, M. Governamentabilidade neoliberal e educação. In: SILVA, Tomaz T. (Org.) O sujeito da educação: estudos foucaultianos. Petrópolis, RJ: Vozes, 1994. p.211-224.

SILVA, T. T. (Org.). O sujeito da educação: estudos foucaultianos. Petrópolis, RJ: Vozes, 1994. 
VEJA, São Paulo: Editora Abril, ed. 2056, abr. 2008

VEJA, São Paulo: Editora Abril, ed. 2072, Páginas amarelas, p. 17-21, ago. 2008 VEJA, São Paulo: Editora Abril, edição 2074, ago. 2008.

Recebido em abril de 2009. Aprovado em julho de 2009 


\section{ANEXO A}

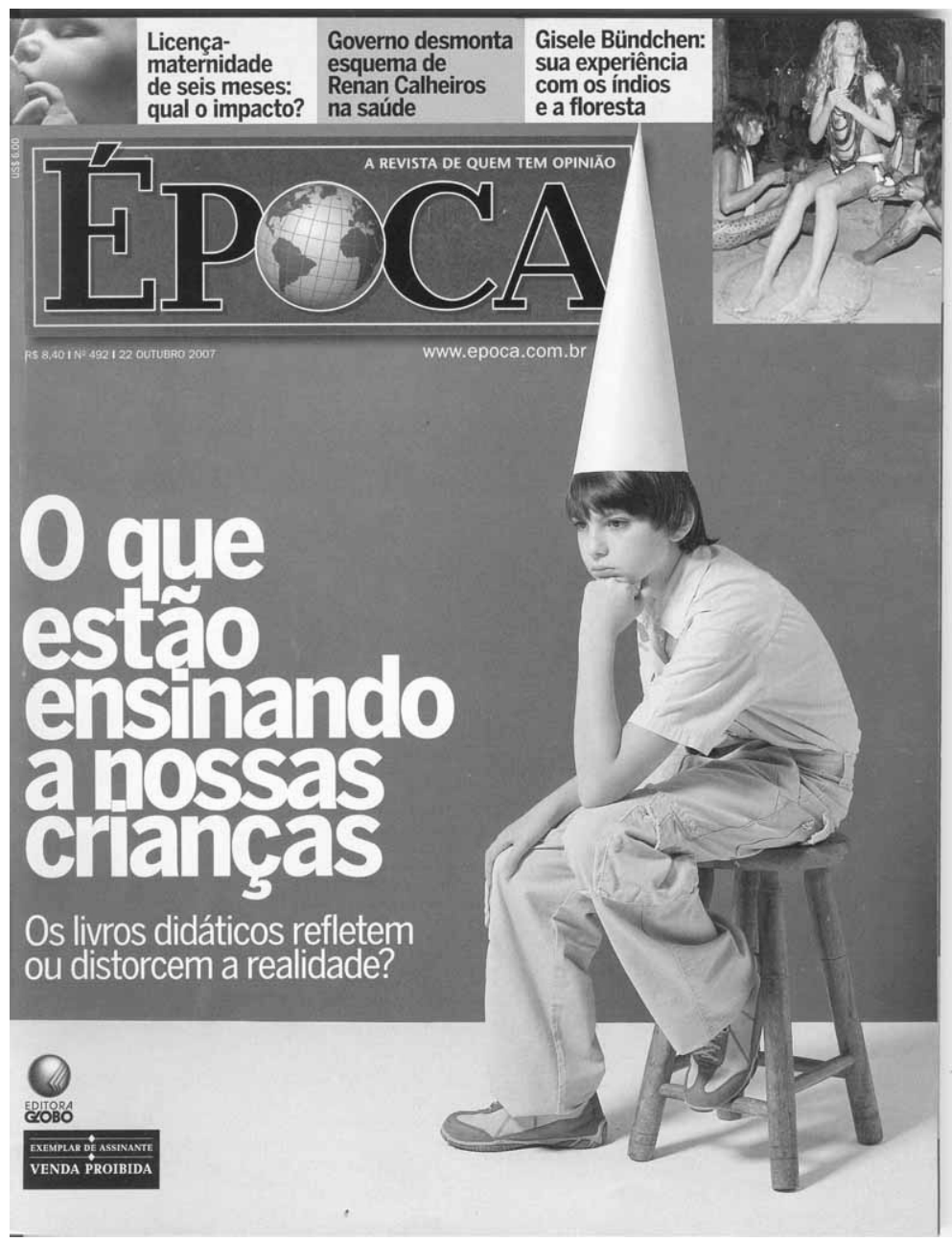




\section{ANEXO B}

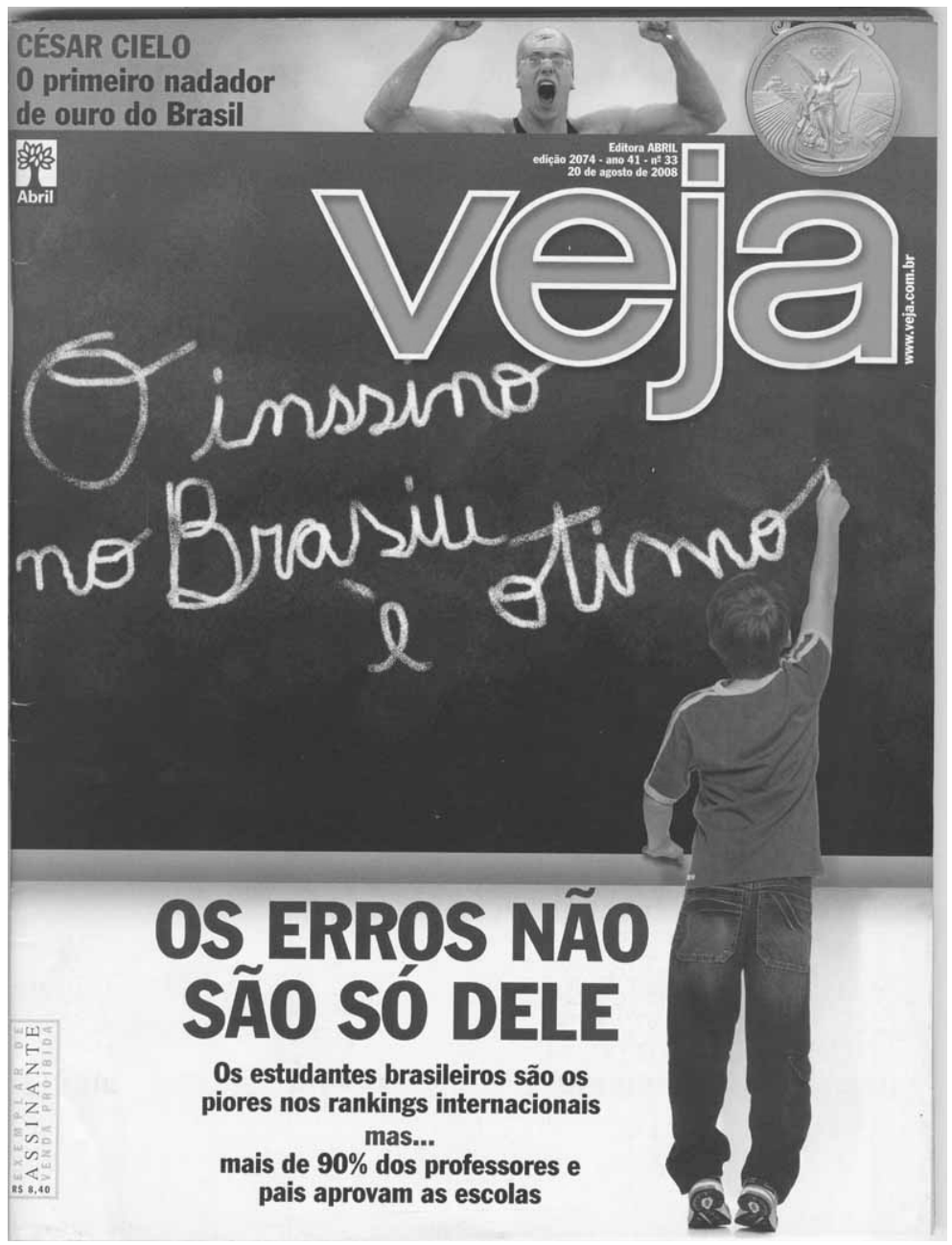




\section{ANEXO C}

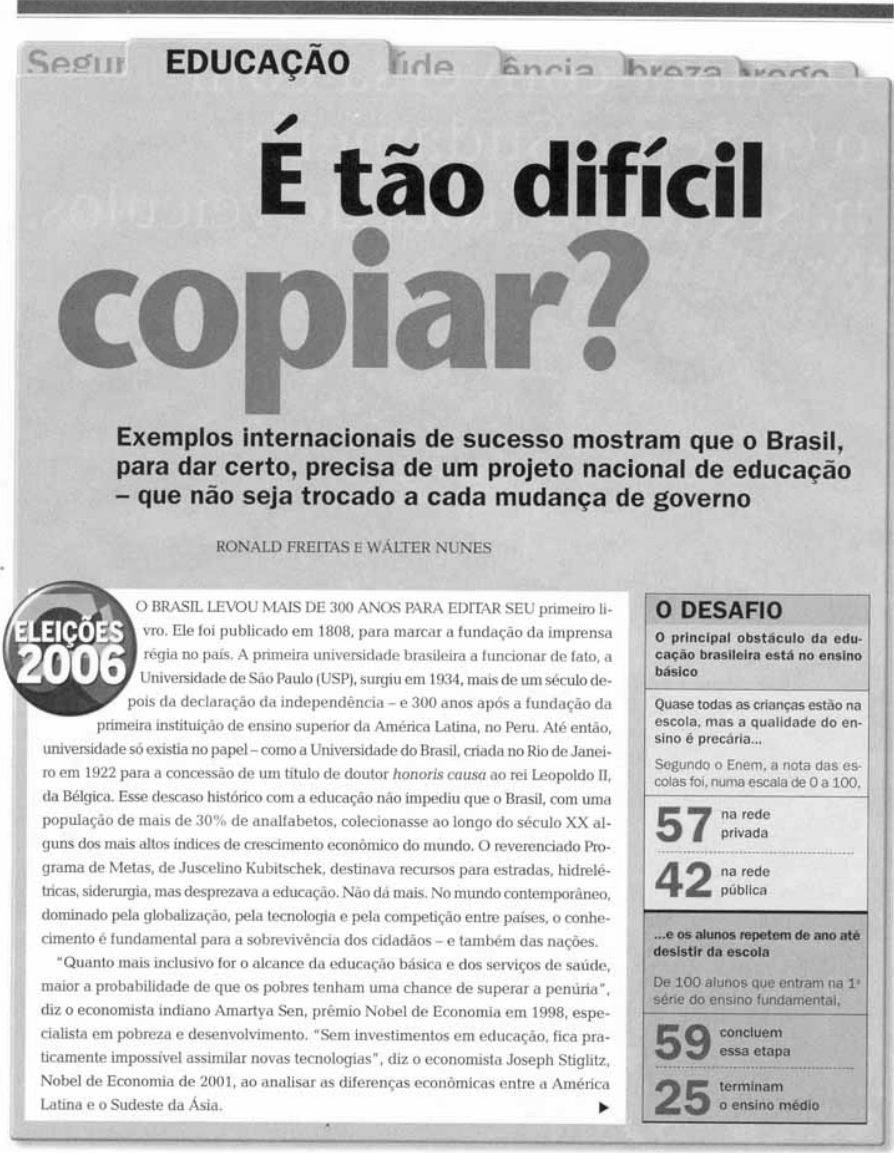

36 


\section{ANEXO D}
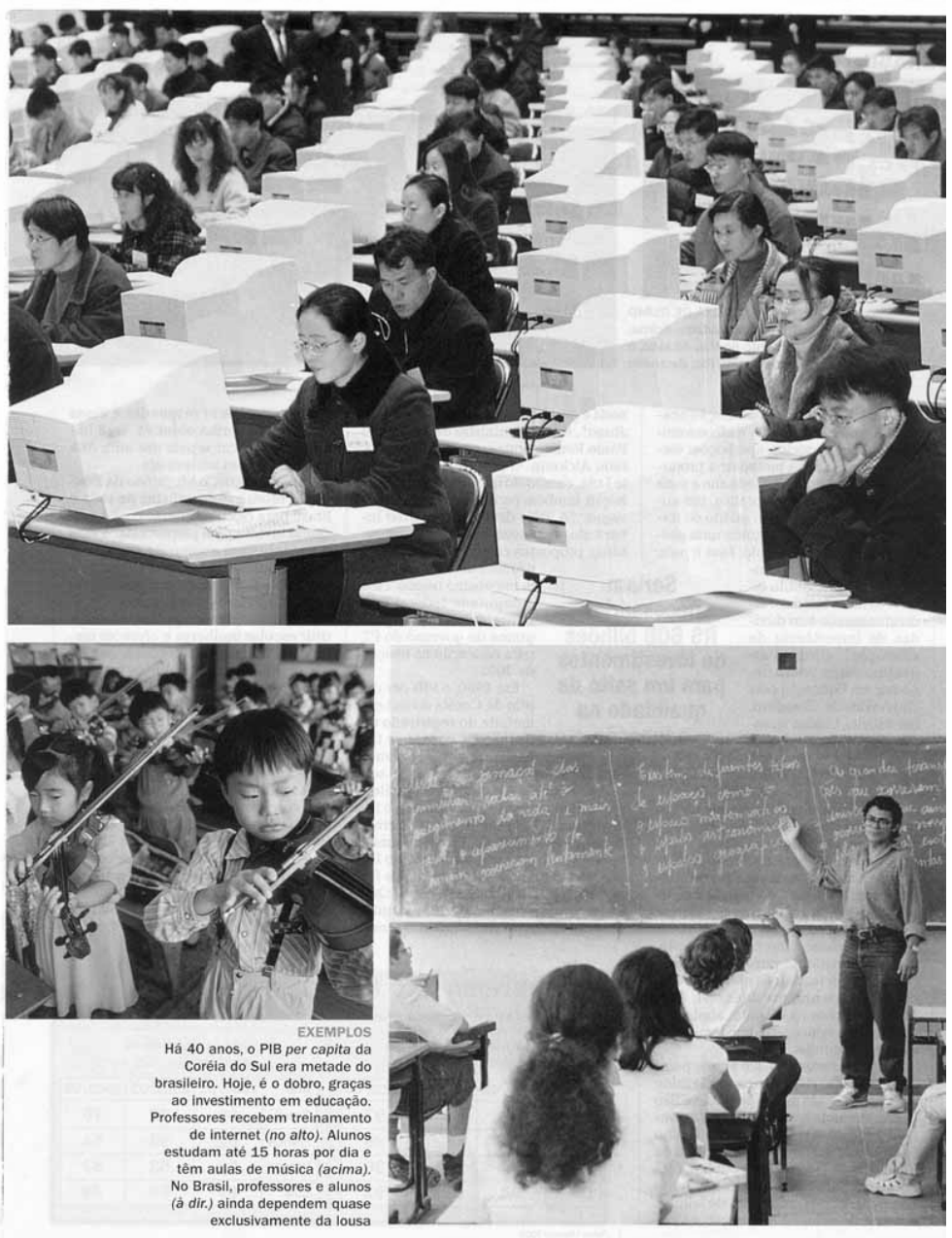


\section{ANEXO E}

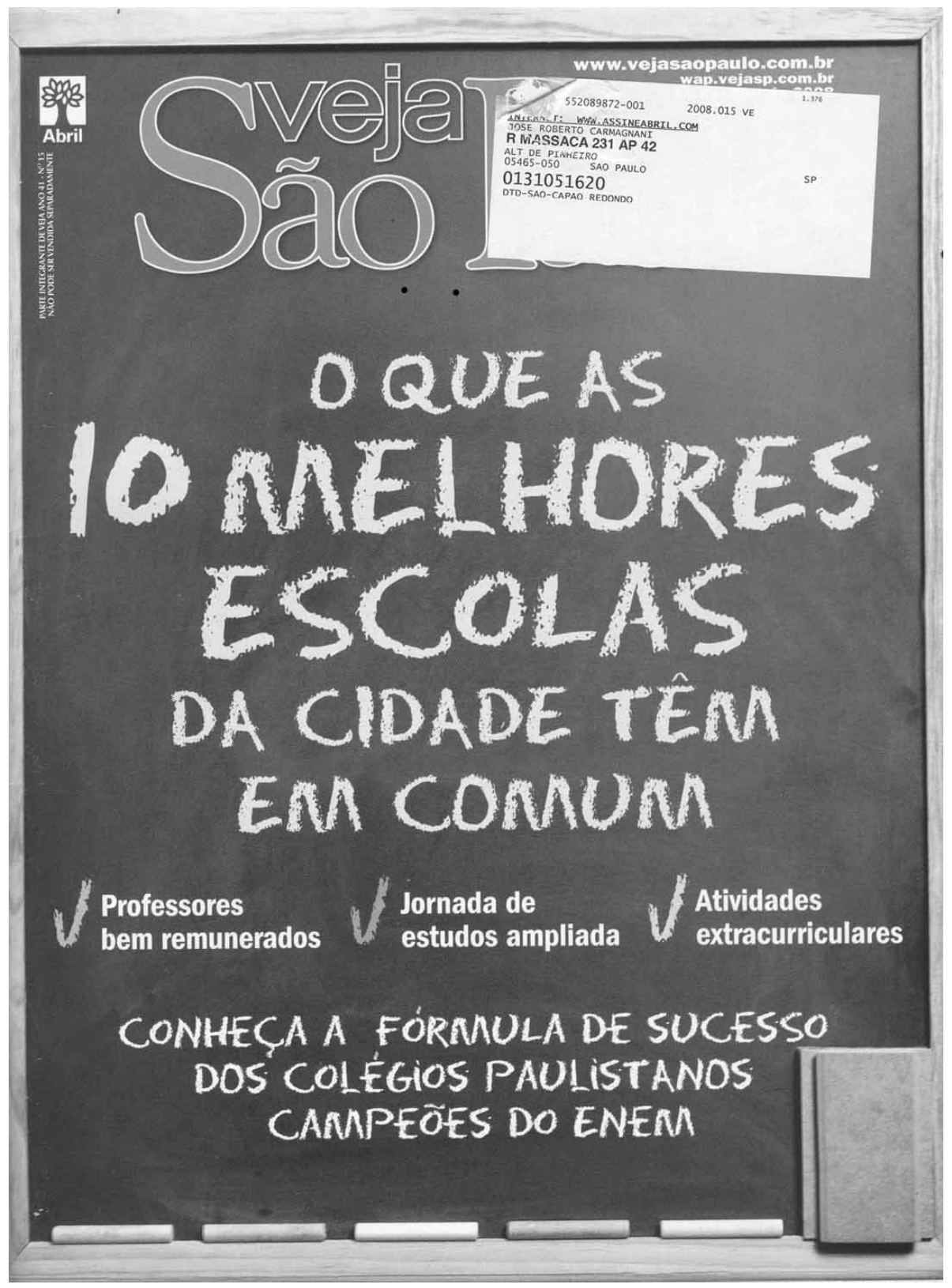

